It is an outstanding privilege to have been invited to this Symposium. Therefore, I lould like first to thank all those concerned with the decision to grant me this honour the occasion of the 8th Symposium on Medicinal Plants of Brazil.

Modern times owe much to traditional medicinal use of plant drugs than a cursory glance would reveal. Plant products have been with man through all history so that their effects be tested and scrutinized through endless trials of a hit or miss nature. It was only after the medicinal chemist had pried into the nature of the chemical secrets of folk remedies that major drugs such as belladona, digitalis, ergot, quinine, reserpine etc., moved into prominence as reliable and immensely used drugs. The untapped vast flora Nigeria in particular and of West Africa in general is well recognizedand the conscious efforts that are being made by scientists to exploit the constituents from the plants growing in this sub-region, which have been proved traditionally to be of medicinal value have started to yield promising results.

The literature is abundant with examples of new and previously known compounds isolated from medicinal plants growing in the sub-region with little thought to the possi ble biological activity tied up with those novel molecules. As pointed out by witkop, (1971), the isolation and structural elucidation of new compounds from plant materials is still just a prologue, the drama does not unfold until these "children" of nature are taken by man and are returned to participate in the dynamics of 1 ife in other systems. This paper reviews the results of research carried out on some medicinal plants growing in West Africa which have been investigated chemically and with proven biological activi ty. This review has been circumscribed by the condition that it should deal with natu ral products of proven chemical structures and showing some kind of biological activity or other. The approach adopted has been rather selective and the presentation is based on a classification according to chemical structure.

\title{
Terpenoids and Sterols
}

Glycoside of 0leanolic acid from Tetrapleura tetraptera ( $f$. Mimosaceae). From the fruit of $\mathrm{T}$. tetraptera oleanolic acid glycoside (1) has been isolated and shown (Adesina et al., 1979) to be responsible for the anti-convulsant properties of the plant material.

Echinocystic acid glycoside is a saponin, from Albizzia adianthifolia, family Mimo

(*) Professor of Pharmaceutical chemistry \& Dean Faculty of Pharmacy, College of Medicine University of Ibadan, Ibadan, Nigeria.

SUPL. ACTA AMAZONICA, 18(1-2):381-392. 1988. 
saceae. The plant is widely distributed in tropical Africa. The saponin, whichwas iso lated from the stem bark and characterised as the aglycone,echinocystic acid (11), showed marked antibacterial activity against gram positive and some gram negative organisms (0laniyi et al., 1976). The demonstration of the antibacterial properties of the saponin content of the plant clearly supports its use in traditional medicine as in the treatment of scabies and other skin complaints.

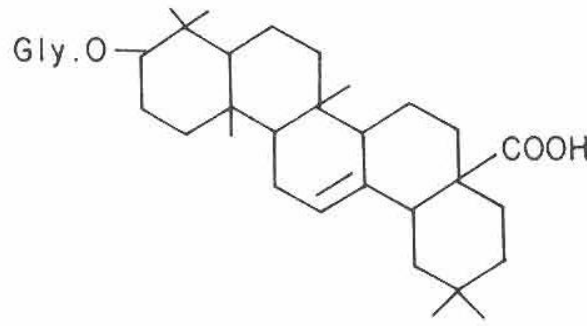

I

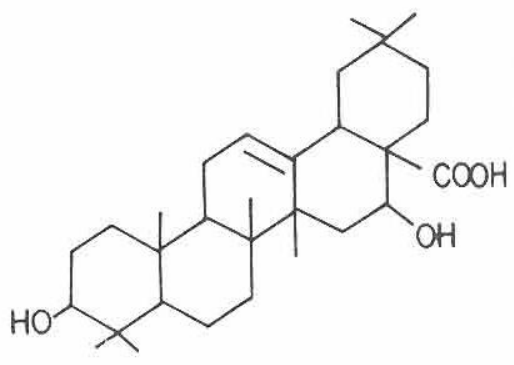

11

Sterols from Momordica foetida: M. foetida f. Cucurbitaceae is used locally to lower blood sugar. A crystalline solid characterised as a homogeneous mixture of B-sitosterol-B-glucoside (III) and 5,25-stigmasta-diene-3B-ol glucoside (IV) was isolated (0laniyi, 1975) from the whole plant and unripe fruit and shown to lower the blood glucose levels of fasting rats over the experimental period of 18 hours comparable with that produced by insulin (Marquis et al., 1977). However, it had no appreciable effect in diabetic animals ot those in which diabetes was induced. A related specie, $\mathbf{M}$. charantia is reported to be a popular folklore remedy for diabetes mel1itus in Indian (Rivera, 1941).<smiles>C=C(C)C(CC)CCC(C)C1CCC2C3CC=C4CC(OCl)CCC4(C)C3CCC12C</smiles> 
Macrocyclic diterpene esters from Euphorbia kamerunica (f. Euphorbiaceae). Plants of the genus Euphorbia produce ingenol and phorbol esters and these compounds are well known for both their acute and chronic toxic effects including pro-inflammatory and tumor-promoting activities (Abo \& Evans, 1981). During routine testing of column iractions from Euphorbia kamerunica it was found that the non-polar fractions which have 10 pro-inflammatory activity demonstrated pronounced cytotoxic activity invitro against rouse TLX/5 lymphoma cells. Three macrocyclic diterpene ingol esters have been isolated from the latex of E. kamerunica growing in Nigeria (Abo \& Evans, 1981). These esters have been shown to have anti-cancer activity in in vitro tests carried out on cultured rat basophilic leukemia cells (Abo, personal communication).

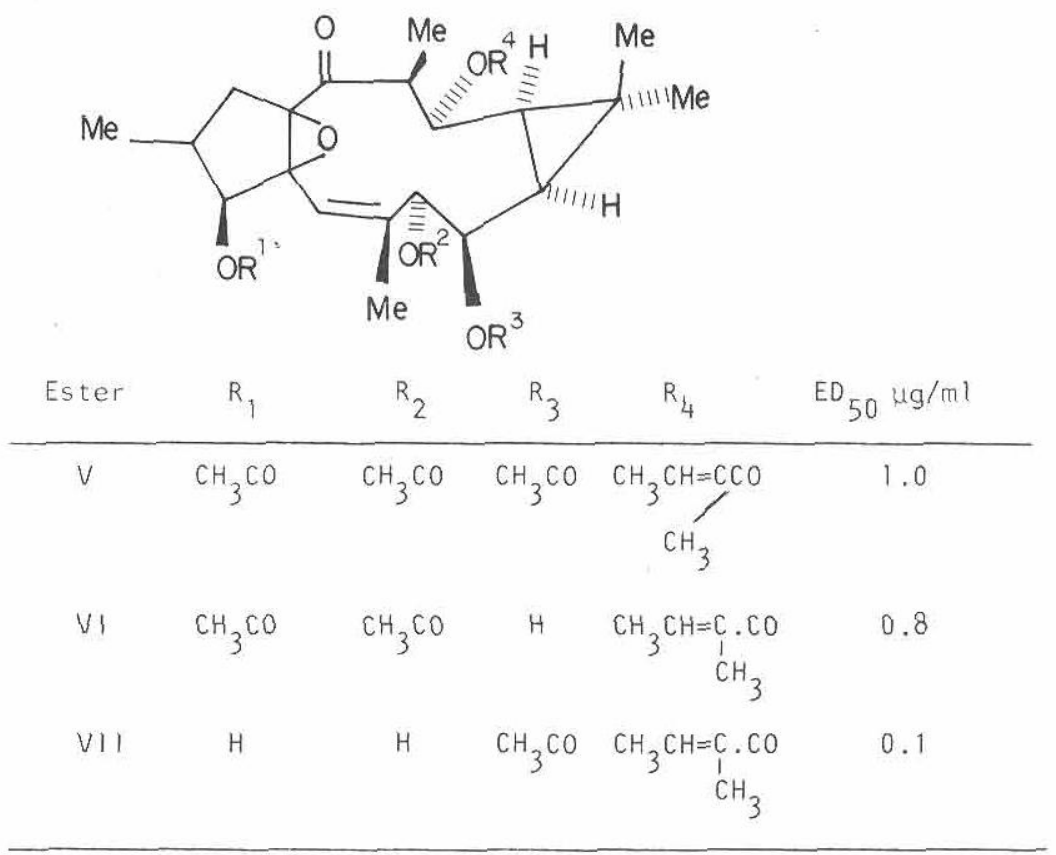

\section{Coumarins}

The identification of vafzelin (VIII) and uvafzel in (IX) and other constituents of Uvaria afzelii ( $f$. Annonaceae) has been reported (Hufford et al., 1980). Uvafzelin, the rost active constituent, was found to be active against Staphlococcus aureus, Bacillus subtilis and Mycobacterium smegmatis but showed no significant anti-tumor or cytotoxic activity (Hufford et al., 1981).<smiles></smiles>

VIII<smiles>[R]OCC1C2=C(Oc3ccccc31)C(C)(C)C(=O)C(C)(C)C2=O</smiles>

IX

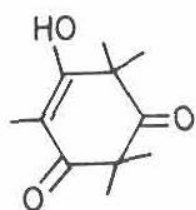


Scopolet in from Tetrapleura tetraptera. T. tetraptera, f. Mimosaceae, is a large perennial tree growing throughout the rain forest of West Africa and is used in folkloric medicine in the management of convulsions, leprosy, inflammation and rheumatic pains. From the fruit of the plant scopoletin ( $X$ ) has been isolated and characterised (Adesina \& 0jewole, 1981; 1983). The cardiovascular and neuromuscular actions of scopolet in have been demonstrated in laboratory animals and the compound has been shown to possess depressor (hypotensive) effects in anaesthesized rats and produced a negative chronotropic and inotropic responses on guinea pig isolated atria. It also possessed a non-specific spas molytic activity on smooth muscles.

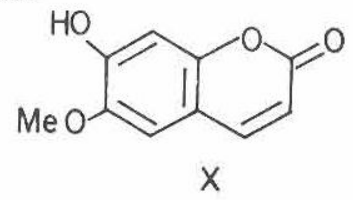

\section{Lignans}

Lignans of Justicia flava. J. flava, f. Acanthaceae, a herbaceous plant which flourishes in West Africa, has abundant use in folk remedies, such as in treating rheumatism fevers, diarrhoea, yaws and as an astringent while the powdered leaves are used inkilling fish. From the acidic fraction of the methanolic extract of the leaves two known lignans isolariciresinol $(X I)$ and helioxanthin $(X \mid I)$ as well as a new lignan, justicinol (XIII) were isolated and characterised (0laniyi \& Powell, 1980). Hehoxanthin and justicinol were shown to be active in vitro in the P-388 lymphocytic leukemia cell culture with an $E_{50}$ of $0.64 \times 10^{1}$ and $<1.0 \times 10^{-1} \mu \mathrm{g} / \mathrm{ml}$ respectively and were partly responsible for the anti-tumor and cytotoxic activity of J. flava extracts (0laniyi \& Oguntimein, 1981). Chemical studies on the methanolic extract of the root yielded two other new lignans named orosunol (XIV) and 8-demethylorosunol (XV). Both lignans showed no appreciable anticancer activity in the test system.<smiles>COc1cc(C2c3cc(O)c(OC)cc3C[C@H](CO)[C@H]2CO)ccc1O</smiles>

XI<smiles>[R]c1cc(-c2c3c(cc4ccc5c(c24)OCO5)COC3=O)cc2c1OCO2</smiles> 
The plant kingdom continues to be a prospective and fruitful hunting ground for new tumour inhibitors. Although many of the compounds found to be active may never be used as drugs and hence will not be of direct value to clinical practice, it is difficult to speculate on their overall value. In some instances their toxicityprecludes their use, but by studying the way in which they act against experimental cancers it is possible to learn something about the mechanism involved in cancer formation.

Piperine and derivaties from Piper guineense. P. guineense, f. Piperaceae, known as West African black peper, occurs in many parts of West Africa, especially Ghana and Nigeria. It is used in many traditional formulations for the treatment of coughs, gastro intestinal disorders, bronchitis, veneral diseases and rheumatism and as a spice in foods. Several active constituents have been isolated from this plant by different research workers (Dwuma-Badu, 1983). Some of the constituents, pipérine. (XVL), dihydropiper ine (XVII), dihydropiperlonguminine (XVIII) and dihydrocubebin (XIX) showed antimicrobial activity against Mycobacterium smegmatis (ATCC 607) at a concentration of $100 \mathrm{\mu g} / \mathrm{mt}$ while in addition, piperine exhibited antimicrobial activity against Candida albicans (ATCC 1023) and dihydropiperine was active against Klebsiella pneumonia (ATCC 1003).<smiles>O=C(/C=C/C=C/c1ccc2c(c1)OCO2)N1CCC2CC1C2</smiles><smiles>O=C(/C=C/CCc1ccc2c(c1)OCO2)N1CCCCC1</smiles><smiles>CC(C)CNC(=O)/C=C/CCc1ccc2c(c1)OCO2</smiles>

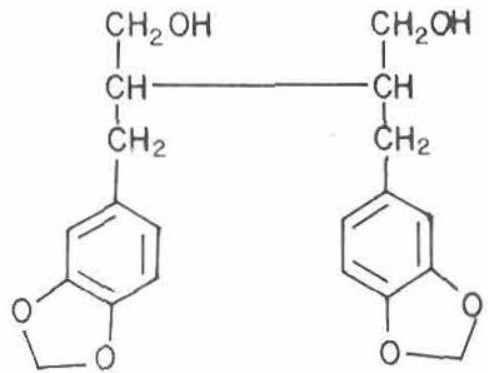

$\mathrm{XIX}$

\section{Alkaloids of Strychnos Species}

Strychnos is a genus which is widely distributed in the tropical areas. Members of this genus are used as arrow poisons in Africa and S. America. Among the West African Strychnos species, (f. Loganiaceae) S. dinklagei, S. afzelii, S. barteri, S. decussata and $S$. usambarensis have been found to contain alkaloids with convulsive and muscle relaxant effects. The first isolation of a convulsive alkaloid from African Strychnos specie was achieved by continual pharmacological screening for convulsive and muscle relaxant effects in the East African S. icaja Baill, leading also to the identification of 4-hydroxystrychnine in that specie. Further screening led to the isolation of new 
tertiary indole alkaloids with a pronounced muscle relaxant effect and producing clonic convulsions in high doses in other species

Ellipticine is the main alkaloid from S. dinklagei Gilg, found in W. Africa and used in local medicine in the treatment of diseases of the mouth, the kidneys and the heart. Ellipticine $(X \mid X b)$ a non-corynane, strychnine-type of alkaloid from Strychnos specie (Michel et al., 1980) was shown to have slight convulsive properties (Sandberget al., 1971; Verpoorte \& Bohlin, 1976).

Akagerine and derivates: 0 -methyl akagerine $(X X)$ from $S$. dinklagei (Verpoorte \& Bohlin, 1976) and S. decussata and 10-hydroxy-17-0-methyl akegerine (XXI) and 10-hydroxy 21-0-methylkribine (XXII) (Rolfsen et al., 1980) from $\mathbf{S}$. decussata and the epi-isomer (XXIII) produced strychnine-like effects having both clonic and tonic convulsions.<smiles>Cc1c2ccccc2c(C)c2c1[nH]c1ccccc12</smiles>

$X \mid X b$

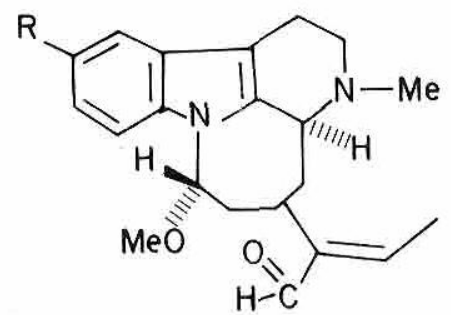

$X X ; R=H$

$X X I ; R=O H$

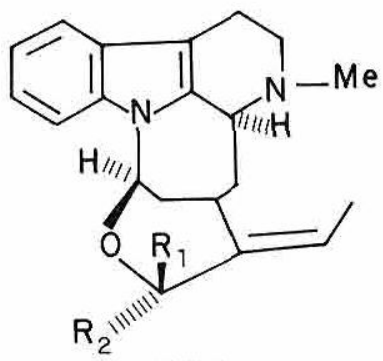

$\begin{array}{ll}X X I I ; & R_{1}=\text { One, }, R_{1}=H \\ X X I I I ; & R_{1}=H ; R_{2}=O m e\end{array}$

II-methoxymacusine (XXIV) the major quaternary alkaloid from the stem and root bark of $\mathbf{S}$. angolensis showed muscle relaxant activity with a minimum lethal dose of $100 \mathrm{mg} / \mathrm{kg}$ (Verpoort et al., 1983)
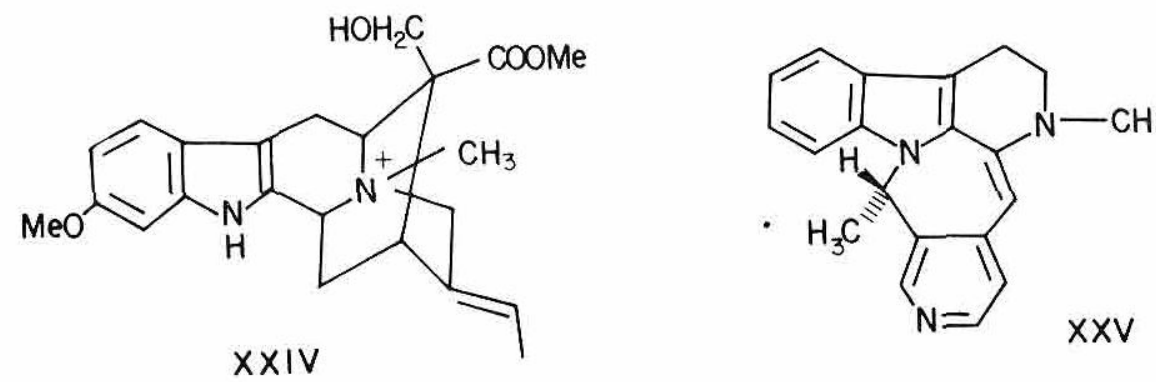

Decussine and decussine-type alkaloids: A new tertiary pentacyclic indole alkaloid was isolated from $S$. decussata stem bark. The structure of the alkaloid, decussine (XXV), was determined by its spectral data and confirmed by X-ray crystallography (Rolfsen et al., 1980). A dose of $50 \mathrm{mg} / \mathrm{kg}$ gave a graded response of $X X$ in the screen grip test while 
iconcentration of $5.1 \mu \mathrm{g} / \mathrm{ml}(16 \mathrm{n} \mathrm{mole} / \mathrm{ml})$ of deccusine reduced the amplitude of the contraction of a rat diaphragm, elicited by electrical stimulation of the phrenic nerve 10 $50 \%$; the effect was not antagonised by synstigmine (neostigmine).

Deccusine, though a tertiary amine, had a pronounced muscle relaxant effect, both in vitro and in vivo on mice, thus possessing a strong action on neuro-muscular junction similar to that of tubocurarine, a quaternary ammonium salt (Rolfsen \& 0laniyi, 1981). Three other tertiary indole alkaloids have also been isolated from $\mathbf{S}$. decussata viz:bisnordihy drotoxiferine, 3, 14-dihydrodecussine (XXVI) and 10-hydroxy-3,14-dihydrodecussine(XXVII). The latter two compounds gave weaker muscle relaxant effects compared with decussine. This observation may be explained as a possible consequence of the double bond between the $3^{-}$and ${ }^{C} 14^{-}$in (XXVI) and (XXVII) for muscule relaxant activity (Rolfsen et al.,1981).

\section{Quaternary alkaloids of $\mathrm{S}$. decussata}

Malindine (XXVIII) is the major quaternary indole alkaloid of a novel structure, obtained from the water soluble fraction of the stem bark of $\mathbf{S}$. decussata.lts structure was determined by a combination of spectral methods and its stereochemistry established by circular dichroism (CD) and Nuclear Overhauser Effect (NOE) experiments. Malindine showed muscle-relaxant effect when injected intraperitoneally in mice and also produced a $50 \%$ reduction in amplitude of the concentrations of a diaphragm-muscle preparation at a dose of $0.5 \mathrm{mg} / \mathrm{ml}$. This compound was shown to be mainly responsible for the muscle relaxant effect of the aqueous extract of the stem bark of S. decussata (0laniyi et al. 1981)

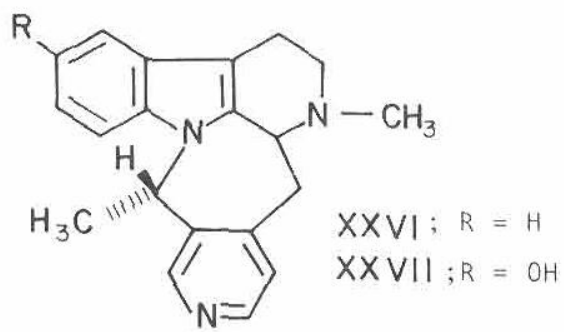

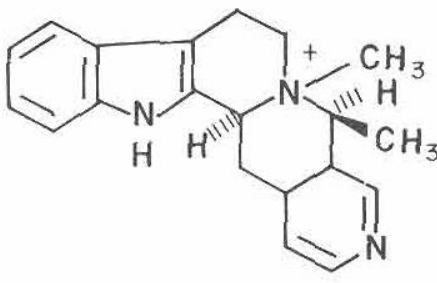

XXVIH

Other quaternary alkaloids isolated from the plant include: Macusine-B, 0-methy 1 acusine-B and alkaloid of macusine A or C-type.

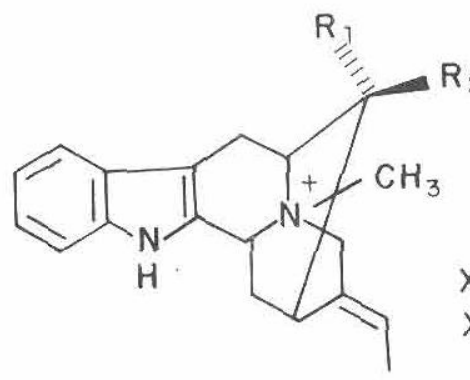

$X X I X ; R_{1}=H, R_{2}=\mathrm{CH}_{2} \mathrm{OH}$

$\mathrm{XXX} ; \mathrm{R}_{1}=\mathrm{H}, \mathrm{R}_{2}=\mathrm{CH}_{2} \mathrm{CH}_{3}$ 


\section{Other Alkaloids}

Alkaloids of Cryptolepsis sanguinolenta; C. sanguinolenta $f$. Asclepiadaceae, an in portant medicinal plant in West Africa, particularly Ghana, is used in traditional medi cine for the treatment of malaria, wound and urinary tract infections. From the root and stem of the plant (Dwuma-Badu et al., 1978) have isolated and characterised fully two alkaloids-quindoline and cryptolepine (XXXI). Cryptolepine, the major alkaloid, has been shown to be active against gram positive and gram negative organisms as well as on rickettsia-like organisms (Dwuma-Badu, 1983). Furthermore (Bamgbose \& Noamesi, 1981) have reported that the alkaloid has anti-inflammatoryactivity and that it inhibits prostaglandin synthesis.

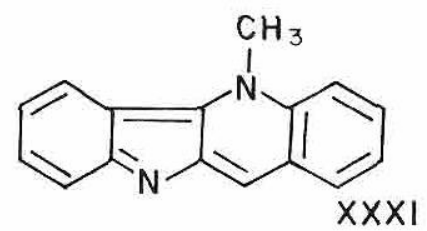

Funiferine (XXXI1), a bisbenzyl isoquinoline alkaloid from Tilicora fumifera and T. dinklagei $f$. Menispermaceae, has been found to be active against acid fast growing micro-organisms (Dwuma-Badu, 1983). Funiferine has also been shown to have some activity in P-388 lymphocytic leukemia and to inhibit the growth of acid fast bacillus Mycobacte rium smegmatis (Geran et al., 1972).

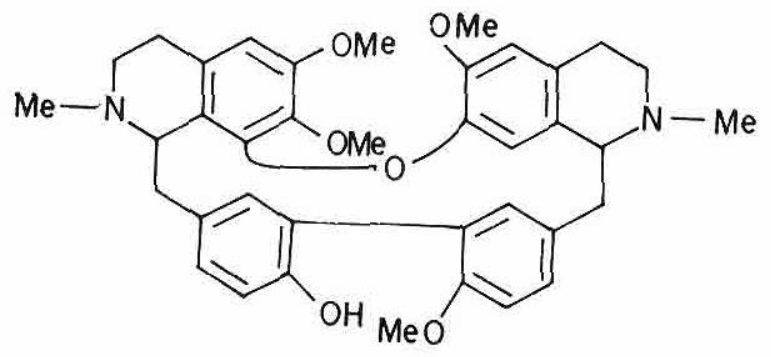

$X X X \|$

Alkaloids of Enantia chlorantha or E. polycarpa. This plant is used traditionally in West Africa for treating ulcers, leprous spots and jaundice. The plant is reported to contain protoberberine-type alkaloids - berberine (XXXIII) and palmatine (XXXIV) (Irvine, 1961). Manske (1975) has reported that palmatine possesses anti-arrhythmic,positive inotropic adrenocorticotropic, anticholinesterase, analgesic and antibacterual action. Bamgbose and co-workers (Bamgbose et al., 1979) have also shown that an aqueous extract of this plant was able to repair or reverse the liver damage produced in experimental rabbits. This observation is significant since it lends support to justify the widespread use of this plant in Nigeria as a cure for jaundice. It is possible that the analgesic, adrenocorticotropic and antibacterial effects of the alkaloid constituents are responsible fot the effective use of the plant in the tratment of jaundice. 


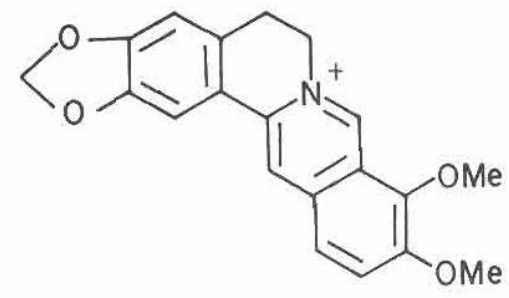

XXX III

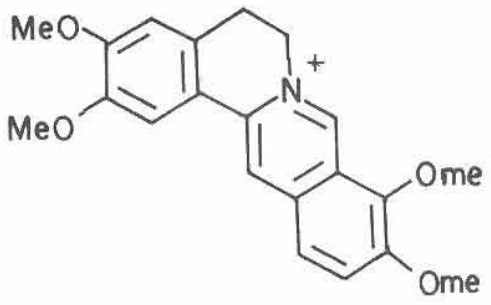

XXXIV

Alkaloids of Alstonia boonei: Alstonia boonei Wild (A. congensis), $f$. Apocynaceae, is widely used as an antipyretic in malaria and sometimes, together with the leaves and roots, in experimental application for rheumatic pains. The main alkaloid of the bark of the plant,echitamine $(X X X V)$, has been observed to cause a fall of the blood pressure in hypertensive cats (Kucera et al., 1973; Marquis, 1975). The drug is reported to potentiate barbiturate sleeping time of mice rats and enhanced the lethality of strychnine (Raymond Hamet, 1941).

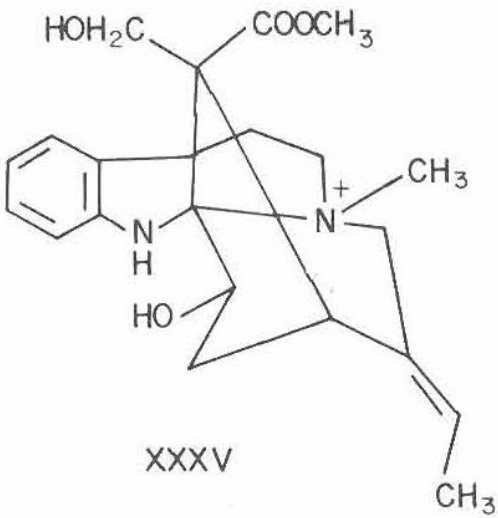

\section{Miscellaneous}

Fagaramide from Zanthoxylum zanthoxyloides: The root bark of Z.xanthoxyloides, f. Rutaceae, is used locally in the treatment of fevers of various aetiologies and sickle cell crises. The anti-inflammatory activity of fagaramide, isolated from the plant ma terial, has been shown (0riowo, 1982) to be effective against carrageenam paw edema in rats and was about twenty times less potent than indomethacin, a non-steroidal anti-in flammatory agent. Fagaramide $(X X X V 1)$ is effective against the prostaglandin phase of the acute experimental inflammatory reaction. It was suggested that part of its antiinflammatory activity is mediated via inhibition of prostaglandin synthesis.

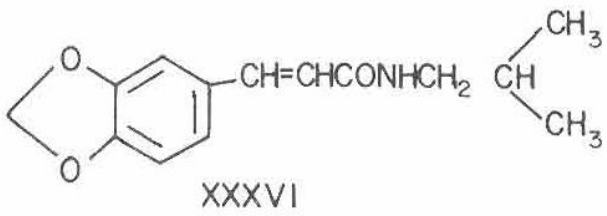


Hydroxybenzoic acids from $Z$. zanthoxyloides. Many constituents have been isolated from the stem bark of this plant. Purification of the aqueous extract of the root re sulted in an antisickling fraction which was shown by gc-ms to be a mixture of some 14 components (Sofowora et al., 1975). 2-Hydroxy-methylbenzoic acid was the only compound characterised from this fraction and it possessed antisickling activity. A patent has been awarded for the IV treatment of sickle cell disease which contains 2-hydroxymethy benzoic acid alone or in a combination with other substituted benzenecarboxylic acids (Sofowora, 1976). Ekong and co-workers (Ekong et al., 1975) have also demonstrated that 3,4-dihydro-2,2-dimethyl-2H-1-benzopyran-6-butyric acid (XXXVII), a derivative of a natural product, xanthoxylol isolated from the roots of $\mathbf{Z}$. zanthoxyloides showed antisickling effects in vitro.<smiles>CC(=O)OCc1ccc2c(c1)CCC(C)(C)O2</smiles>

\section{XXXVII}

Kolanone from Garcinia kola. G. kola is a large forest tree found throughout West and West Central Africa. Its seeds and chewing sticks are thought to aid oral hygiene presumably by exerting an antibacterial action in the mouth. From the light petroleum extract of the fruit pulp, a novel polyisoprenylbenzophenone named kolanone (XXXVIII) has been isolated and shown to exhibit significant antimicrobial activity against a range of organisms (Hussain et al., 1982). Kolanone is at least partially responsible for the antiseptic properties that local usage of G. kola implies.

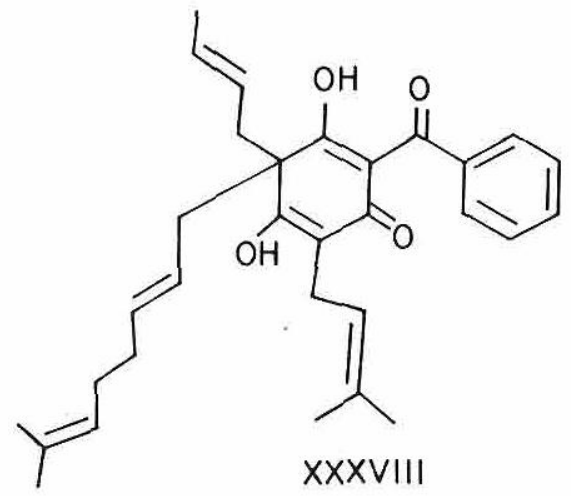

One of the prerequisites for the success of primary healthcare is the availability and use of suitable drugs. Plants have ever been a common source of medicaments, either in the form of traditional preparations or as pure active principles. It is gratifying to note that the successes of the past on medicinal plant research in the West African subregion, through a more thorough and adequate scientific study and on a systematic inter disciplinary basis, are now providing the necessary stimulus and encouragement for further 
work. There is no doubt that natural product studies involving search for new biologicalty active substances will present unique challenges but one must be aware of the problems inherent in this kind of work, especially as regards obtaining appropriate funds and securing the services of co-operative pharmacologists to ensure suitable biological evalu ations of crude drug extracts and isolated pure compounds. These problems are more compounded in the third world countries with very limited infrastructural, manpower and financial resources. Lack of research based pharmacentical industries in the sub-region has contributed most adversely to the possible exploitation and utilization of results of proven investigations. Regardless of these limitations we need to press om ir our efforts to pry into the frontier areas of scientific drug innovation as we must continue to identify new drugs to combat diseases, particularly those that have defied modern medical science and also we must identify new sources of existing drugs and discover new materials which could be used as precursors or templates in drug synthesis. In this way, I believe, we shall be able to make a contribution towards the development of better drugs for the control of prevalent tropical diseases which have continued to plague the developing countries.

\section{References}

Abo, K. - (s.d). Personal communication.

Abo, K. \& Evans, F. J. - 1981. Phytochemistry 20: 2535.

Adesina, S. K. \& Sofowora, E. A. - 1979. Planta Medica, 36: 270.

Adesina, S. K. \& Ojewole, J. 0. - 1983. Planta Medica, 49: 46, 99, and J. African Med. - 1981. J. African Med. Plants 4: 27.

Bamgbose, S. O. A.; Adegoke, E. A.; Adewoye, H. O.; Ogunwuyi, J. O. - 1979.J. Afr. Med. Plants, 91.

Bamgbose, S. O. A. \& Noamesi, B. K. - Planta Medica, 41: 392.

Dwuma-Badu, D.; Ayim, J. S. K.; Fiagbe, N. L. Y.; Knapp, J. Er.; Schiff,O.L.Jnr. \& Slat kin, D. J. - 1978. J. Pharm. Sci., 67: 433.

Dwuma-Badu, D. - 1983. Proceedings of the 5th Internacional Symposium on Medicinal Plants University of Ife, Ile-Ife, Nigeria. In Press.

Ekong, D. E. U.; Okogun, J. I.; Enynihi, V.; Balogh, Nair, V.; Nakanishi,K.; Natta, C. 1975. Nature (Lond), 528: 743 .

Geran, R. I.; Greenberg, N. H.; MacDonald, M. H.; Schumacher, A. M.;Abbott,B. J. - 1972. Cancer Chemotherapy Report, 3: 25.

Hufford, C. D.; Oguntimein, B. O.; Engen, D. V.; Muthard, D.; C1ardy, J. - 1980. J.Amer. Chem. Soc., 102: 7365 . 
Hufford, C. D.; Oguntimein, B. O.; Baker, J. K. - 1981. J. Org. Chem., 46: 3073. Hussain, R. A.; Owegby, A. G.; Parimoo, P.; Waterman, P. G. - 1982. P1anta Medica, 44: 78.

Irvine, F. R. - 1961. Woody plants of Ghana, Oxford Univ. Press.

Kucera, M.; Marquis, V. O.; Okuyemi, A. 0. - 1973. African J. Pharm., 3: 228.

-- - 1973. Pharm. Sci., 3: 228.

Manske, R. H. F. - 1975. The Alkaloids, Vo1. XV, Academic Press, New York.

Marquis, V. O. - 1975. Organization of African Unity Symposium, Cairo, item 6/32, 159. Marquis, V. O.; Adanlawo, T. A.; Olaniyi, A. A. - 1977. Planta Medica, 31: 376.

Miche1, S.; Tillequin, F.; Koch, M.; Ass., L. Oke - 1980. J. Nat. Prod., 43: 294.

Olaniyi, A. A. - 1975. Lloydia, 38: 361.

Olaniyi, A. A.; Ogunlana, E. O.; Fakoya, A. A.; 0latunde, J. A. - 1976. J. Med. and Pharm. Marketing, 3: 135 .

Olaniyi, A. A. \& Oguntimein, B. O. - 1981. Proceedings of the 4th International Symposi um on Medicinal Plants, 1981, Univ. of Ife, Ile-Ife, Nigeria. In Press.

Olaniyi, A. A. \& Powe11, J. W. - 1980. J. Nat. Prod., 43: 482.

Olaniyi, A. A.; Rolfsen, W. N. A.; Verpoorte, R. - 1981. Planta Medica, 43: 353.

Oriowo, M. A. - 1982. Planta Medica, 44: 54.

Raymond-Hamet, R. - 1941. Compte Randu des Sceances de 1a Societe de Biologie Paris, 135: 1565 .

Rivera, G. - 1941. Amer. J. Pharm., 113: 281.

Rolfsen, W. N. A.; Olaniyi, A. A.; Hylands, P. J. - 1980. J. Nat. Prod., 43: 97.

Rolfsen, W. N. A.; Olaniyi, A. A.; Sandberg, F.; Kvick, A. H. - 1980. Acta Pharm. Suecica, 17: 105 .

Rolfsen, W. N. A. \& Olaniyi, A. A. - 1981. Drugs of the future, Vo1. VI, 276.

Rolfsen, W. N. A.; Olaniyi, A. A.; Verpoorte, R.; Bohlin, L. - 1981. J. Nat. Prod., 44: 415 .

Sandberg, F.; Verpoorte, R.; Cronlund, A. - 1971. Acta Pharm. Suecica, 8: 341.

Sofowora, E. A.; Isaacs Sodeye, W. A.; Ogunkoya, L. O. - 1975. Lloydia, 38: 169.

Sofowora,E. A. - 1976. Ger offen patent 2,523,108 (1975) thro. C. A.,84,111679g (1976).

Verpoorte, R. \& Bohlin, L. - 1976. Ibid, 13: 245. Acta Pharm Suecica, 13: 245.

Verpoorte, R.; Bohlin, L.; Dwuma-Badu, D.; Rolfsen, W.; Strombon, J. - 1983. J.Nat.Prod. 46: 572 .

Witkop, B. - 1971. Experienta, 27: 1121. 